\title{
Synergistic interaction between Diclofenac and Pyrilamine on nociception, inflammation and gastric damage in rats
}

\begin{tabular}{|r|l|}
\hline Journal: & Canadian Journal of Physiology and Pharmacology \\
\hline Manuscript ID & cjpp-2016-0306.R1 \\
\hline Manuscript Type: & Article \\
\hline Date Submitted by the Author: & 25-Jul-2016 \\
\hline Complete List of Authors: & $\begin{array}{l}\text { Ortiz, Mario; Universidad Autonoma del Estado de Hidalgo Instituto de } \\
\text { Ciencias de la Salud Area Academica de Medicina }\end{array}$ \\
\hline Keyword: & $\begin{array}{l}\text { Diclofenac, Pyrilamine, Synergism, Nociception and Inflammation, Gastric } \\
\text { Damage }\end{array}$ \\
\hline \multicolumn{2}{|l}{} \\
\hline
\end{tabular}

\section{SCHOLARONE \\ Manuscripts}




\title{
Synergistic interaction between Diclofenac and Pyrilamine on nociception, inflammation and gastric damage in rats
}

\author{
Mario I. Ortiz ${ }^{*}$ \\ Área Académica de Medicina del Instituto de Ciencias de la Salud, Universidad Autónoma \\ del Estado de Hidalgo, Pachuca, Hidalgo, México
}

\footnotetext{
*Corresponding author:

Mario I. Ortiz, Ph.D.

Laboratorio de Farmacología

Área Académica de Medicina del Instituto de Ciencias de la Salud Universidad Autónoma del Estado de Hidalgo

Eliseo Ramírez Ulloa 400, Col. Doctores

Pachuca, Hgo.

42090, MEXICO

Phone Number: +52-77-1717-2000 Ext. 2361

Fax Number: +52-77-1717-2000 Ext. 2361

E-mail:mortiz@uaeh.edu.mx
} 


\begin{abstract}
Experiments using non-steroidal anti-inflammatory drugs (NSAIDs) alone have produced limited antinociceptive effects in animal models. For this reason, the number of studies involving the administration of NSAIDs along with an adjuvant drug harboring different mechanisms of action has increased enormously. Here, combinations of diclofenac and pyrilamine were used to determine their influence on nociception (formalin test), inflammation (paw inflammation produced by carrageenan), and gastric damage in rodents. Diclofenac, pyrilamine, or combinations of diclofenac and pyrilamine produced antinociceptive and anti-inflammatory effects in the rat. The systemic administration of diclofenac alone and in combination with pyrilamine produced significant gastric damage. Effective dose (ED) values were determined for each individual drug, and isobolograms were prepared. The theoretical ED values for the antinociceptive (systemic: $35.4 \mathrm{mg} / \mathrm{kg}$ and local: $343.4 \mu \mathrm{g} / \mathrm{paw})$ and the anti-inflammatory $(37.9 \mathrm{mg} / \mathrm{kg})$ effects differed significantly from the experimental ED values (systemic antinociception: $18.1 \mathrm{mg} / \mathrm{kg}$, local antinociception: 183.3 $\mu \mathrm{g} / \mathrm{paw}$ and anti-inflammation: $10.6 \mathrm{mg} / \mathrm{kg}$ ). Therefore, we concluded that the interactions between diclofenac and pyrilamine are synergistic. Our data suggest that the diclofenacpyrilamine combinations can interact at the systemic and local peripheral levels, thereby offering a therapeutic alternative for the clinical management of inflammatory pain.
\end{abstract}

Key Words: Diclofenac; Pyrilamine; Synergism; Nociception; Inflammation; Gastric Damage. 


\section{Introduction}

The treatment of painful and inflammatory conditions may include pharmacological and nonpharmacological therapies. Due to the role played by prostaglandins on these conditions, nonsteroidal anti-inflammatory drugs (NSAIDs) are widely prescribed as an initial or definitive therapy (Nalamachu 2013). However, the clinical management of some moderately to severely painful and/or inflammatory conditions using NSAIDs alone could produce a limited therapeutic effect and fail to provide adequate pain relief for the patients (Nalamachu 2013; Ortiz 2010). Therefore, several international guidelines recommend the use of NSAIDs along with an adjuvant analgesic drug to produce more effect pain relief. In this sense, the combination of NSAIDs with acetaminophen, antidepressants, anticonvulsants, local anesthetics, opioids, or antihistamines is recommendable in situations of moderate to severe pain (Moore et al. 2015; Ortiz 2010; Ortiz et al. 2009). In this particular case, the two main challenges over the past decades were to improve the analgesic efficacy and minimize the side effects. Thus, researchers continue to experiment with different combinations of analgesic drugs in animal models of pain and inflammation (Moore et al. 2015). Later, clinical researchers analyzed these findings in order to investigate their possible clinical utility.

The contribution of histamine and its receptors in neurogenic inflammation and nociception has been widely demonstrated in preclinical models (Rosa and Fantozzi 2013). In clinical conditions, some antihistamines have demonstrated analgesic effects when used as a monotherapy. Several clinical studies completed between the 1960 s and 1980s found that significant analgesic effects were produced by the single administration of the histamine receptor blockers diphenhydramine, orphenadrine, pyrilamine, cimetidine, phenyltoloxamine, and hydroxyzine (Fujita et al. 2013; Raffa 2001; Rumore and Schlichting 1986). More recently, Fujita et al. (2013) found that the histamine $\mathrm{H}_{1}$-receptor antagonist diphenhydramine was able to produce analgesia as a simple entity. The authors proved that a $1 \%$ 
diphenhydramine ointment produced a better analgesic activity than indomethacin when given to patients with osteoarthritis and/or osteoarthritis pain (Fujita et al. 2013). However, the use of histamine $\mathrm{H}_{1}$-receptor antagonists alone for the relief of clinical pain is not authorized (Fujita et al. 2013). Therefore, antihistaminic agents are commonly used in combination with analgesics, NSAIDs, caffeine, or decongestants in the management of pain and/or common cold symptoms (Kim et al. 2015; Ortiz 2010; Ortiz et al. 2009). Recently, our group demonstrated that, in Mexican students, the most common medication prescribed by physicians and used in self-medication (SM) to treat dysmenorrheic pain was an over-the counter (OTC) medication containing a mixture of paracetamol (analgesic), pamabrom (xanthine with diuretic activity), and pyrilamine (histamine $\mathrm{H}_{1}$-receptor antagonist) (Ortiz 2010; Ortiz et al. 2009). In this case, it is possible to suggest that the pamabrom-induced pharmacological effects are involved in the analgesic activities produced by paracetamol and pyrilamine in the management of pain in women with primary dysmenorrhea. The antinociceptive and anti-inflammatory effects and the gastric damage potential resulting from the combination of pyrilamine with an NSAID such as diclofenac have never been studied. Therefore, we aimed to determine the type of drug interaction produced by a diclofenacpyrilamine combination on nociception, inflammation and gastric damage in rodents.

\section{Materials and Methods}

\section{Animals}

Female rats (Wistar strain; aged 7-9 weeks; weight range 180-220 g) were used in our study. Five to eight animals were used per experimental group. Efforts were made to minimize animal suffering and to reduce the number of animals used. Each rat was used in only one experiment. The study was conducted according to the ethical guidelines previously reported 
by Zimmermann (1983), and all experiments were approved by an independent committee at our Institution (CINVESTAV, IPN, México, D.F. Mexico).

\section{Drugs}

Formaldehyde, diclofenac, and pyrilamine were obtained from Sigma (St. Louis, MO, USA). Diclofenac and pyrilamine were dissolved in $0.9 \%$ saline solution (vehicle).

\section{Measurement of Antinociceptive Activity}

The rat paw $1 \%$ formalin test was used to assess nociceptive and antinociceptive effects (Ortiz 2011). Fifty microliters of $1 \%$ formalin were injected subcutaneously (s.c.) in the right hind paw, and the flinching behavior was quantified. The nociceptive behavior showed a biphasic pattern (Ortiz 2011). The number of flinches yielded a biphasic curve, and the area under the curve was calculated for both phases.

\section{Local peripheral Antinociception}

Twenty minutes before the formalin injection, local peripheral injections with vehicles or different doses of diclofenac $(10,30,100$ and $300 \mu \mathrm{g} / \mathrm{paw})$, pyrilamine $(30,100,300$ and $1000 \mu \mathrm{g} / \mathrm{paw})$, or a diclofenac-pyrilamine combination $(42.9,85.8,171.7$ and $343.4 \mu \mathrm{g} / \mathrm{paw})$ were performed. The tester was blinded to the administration of the different treatments.

\section{Systemic Antinociception}

Thirty minutes before injecting the $1 \%$ formaldehyde solution, vehicle or different doses of the tested formulations were administered orally, including diclofenac $(10,18,30$ and 56 $\mathrm{mg} / \mathrm{kg})$, pyrilamine $(3,10,30$ and $56 \mathrm{mg} / \mathrm{kg})$, or a diclofenac-pyrilamine combination (4.4, 8.8, 17.7 , and $35.4 \mathrm{mg} / \mathrm{kg}$ ). The tester was blinded to the administration of the different treatments. All treatments were administered in a volume of $4 \mathrm{ml} / \mathrm{kg}$.

\section{Measurement of carrageenan-induced paw inflammation}

Inflammation and drug-induced anti-inflammatory effects were evaluated using the carrageenan-induced paw edema test (Bignotto et al. 2009; Ortiz et al. 2010a). First, the 
volume of the paw was measured with a plethysmometer (Ugo Basile Model 7140 Comerio, Italy). Second, vehicle or different doses of diclofenac (3,10, 18 and $30 \mathrm{mg} / \mathrm{kg}$ ), pyrilamine $(3,10,30$ and $56 \mathrm{mg} / \mathrm{kg})$, or a diclofenac-pyrilamine combination $(4.7,9.5,18.9$ and 37.9 $\mathrm{mg} / \mathrm{kg}$ ) were administered orally. Thirty minutes after drug administration, 100 microliters of a $1 \%$ carrageenan solution were administered subcutaneously (s.c.) into the paw. Finally, six hours after the carrageenan administration, the paw volumes were measured (Bignotto et al. 2009; Ortiz et al. 2010a). The paw inflammation tester was blinded to the administration of the different treatments. All treatments were administered in a volume of $4 \mathrm{ml} / \mathrm{kg}$.

\section{Measurement of gastric damage}

Independent groups of animals were given an oral (p.o.) dose of vehicle or treatment. The different treatments were diclofenac (10-56 mg/kg), pyrilamine $(3-56 \mathrm{mg} / \mathrm{kg})$ or a diclofenacpyrilamine combination $(4.4-35.4 \mathrm{mg} / \mathrm{kg}$ ). The drug doses employed in these experiments are the same doses used in the systemic antinociception experiments. The rats were euthanized three hours after drug administration.

Other groups of animals orally received vehicle or a different dosage of drug, including diclofenac (3-30 mg/kg), pyrilamine (3-56 mg/kg), or a diclofenac-pyrilamine combination $(4.7-37.9 \mathrm{mg} / \mathrm{kg})$. The drug doses employed in these experiments are the same doses used in the anti-inflammation experiments. The rats were euthanized six hours after drug administration. To evaluate the gastric damage produced by the drugs, the number of hemorrhagic lesions in the stomach of the tested rats was scored as previously reported (Ortiz et al. 2010a; 2010b).

\section{Motor coordination test}

The capacity of the drugs to alter motor coordination was evaluated using the rotarod test. Motor coordination was assessed before and at 1, 3 and $6 \mathrm{~h}$ after the administration of vehicle 
$(1 \mathrm{ml})$, diclofenac $(56 \mathrm{mg} / \mathrm{kg})$, pyrilamine $(56 \mathrm{mg} / \mathrm{kg})$, or a combination of diclofenac $(13.4$ $\mathrm{mg} / \mathrm{kg})+$ pyrilamine (24.4 mg/kg), as published previously (Ortiz 2013; Ortiz et al. 2012).

\section{Data Analysis}

\section{Antinociception}

The area under the curve (AUC) of the systemic and local peripheral antinociceptive effects produced by each individual and combined drug regimen was calculated as previously described (Ortiz 2013; Ortiz et al. 2012). The percentage of antinociception for the second phase of the assay was determined according to the following equation (Ortiz 2013; Ortiz et al. 2012): \% antinociception $=\left[\left(A U C_{\text {vehicle }}-A U C_{\text {post-drug }}\right) / A U C_{\text {vehicle }}\right] \times 100$.

\section{Anti-inflammation}

Differential paw volume (DPV) data were determined using the following formula: DPV = paw volume at $6 \mathrm{~h}$ - basal paw volume. The percentage of anti-inflammation for each drug treatment was calculated according to the following equation (Ortiz et al. 2010a): \% antiinflammation $=\left[\left(D P V_{\text {vehicle }}-D P V_{\text {post-drug }}\right) / D P V_{\text {vehicle }}\right] \times 100$.

\section{Drug combinations}

The effective dose $30\left(\mathrm{ED}_{30}\right)$ for systemic antinociception and effective dose $40\left(\mathrm{ED}_{40}\right)$ for local peripheral antinociception and anti-inflammation were calculated as reported by Tallarida (2000). The $\mathrm{ED}_{30}$ and $\mathrm{ED}_{40}$ are the dose that produced the $30 \%$ and $40 \%$ of the maximal observable effects, respectively. The interactions between diclofenac and pyrilamine were characterized by isobolographic exploration (Ortiz 2013; Ortiz et al. 2010a; 2010b; 2012; Wagner and Ulrich-Merzenich 2009). Because the biological responses induced by diclofenac and pyrilamine were lower than 50\%, we used the $\mathrm{ED}_{30}$ for systemic antinociception and the $\mathrm{ED}_{40}$ for local antinociception and anti-inflammation (Ortiz 2013; Ortiz et al. 2010a; 2010b). Then, the concomitant administration of both drugs (diclofenac + pyrilamine) was determined based on the $\mathrm{ED}_{30}$ or $\mathrm{ED}_{40}$ values of each individual drug. 
Experimental dose-response curves were obtained with the drug combinations shown in Table 1, and the experimental $\mathrm{ED}_{30}$ or $\mathrm{ED}_{40}$ values were calculated from these curves for each drug combination.

Table 1 should be here.

The theoretical $\mathrm{ED}_{30}$ or $\mathrm{ED}_{40}$ values of the drug mixtures were calculated from the sum of the effects of each individual drug (e.g., diclofenac + pyrilamine combination theoretical $\mathrm{ED}_{30}$ $=$ diclofenac $\mathrm{ED}_{30} / 2+$ pyrilamine $\mathrm{ED}_{30} / 2$ ). These theoretical $\mathrm{ED}_{30}$ or $\mathrm{ED}_{40}$ values were statistically contrasted with the experimentally obtained $\mathrm{ED}_{30}$ or $\mathrm{ED}_{40}$ values, respectively (Ortiz 2013; Ortiz et al. 2010a; 2010b; Tallarida 2002). To enhance the analysis of the results, an interaction index $(\gamma)$ value was obtained using the following formula: $\gamma=$ experimental $E D_{30}$ or $E D_{40}$ of combinations/ theoretical $E D_{30}$ or $E D_{40}$ of combinations. The $\gamma$ value indicated the kind of pharmacological interaction as follows: $\gamma=1$, additive interaction; $\gamma>1$, antagonism; $\gamma<1$, synergistic interaction (Ortiz 2013; Ortiz et al. 2010a; 2010b; Tallarida 2002).

\section{Statistical Analyses}

The dose-response curves were evaluated for significance using the one-way ANOVA and Dunnett's test. The comparison between theoretical and experimental values was realized using the Student's $t$-test (Ortiz 2013; Ortiz et al. 2010a; 2010b; Tallarida 2000). An experimental $\mathrm{ED}_{30}$ or $\mathrm{ED}_{40}$ value significantly inferior to the theoretical $\mathrm{ED}_{30}$ or $\mathrm{ED}_{40}$ value, respectively, indicated a synergistic interaction. The results were considered statistically significant when $p<0.05$.

\section{Results}

\section{Antinociceptive and anti-inflammatory activities produced by diclofenac and pyrilamine}

The local peripheral administration of formalin produced a flinching behavior indicative of nociception. The local peripheral and systemic administration of diclofenac and pyrilamine 
produced a dose-dependent antinociceptive effect during the second phase $(p<0.05$; Figures 1 and 2). The $\mathrm{ED}_{40}$ values for local diclofenac and pyrilamine administration were $207.1 \pm$ $19.3 \mu \mathrm{g} / \mathrm{paw}$ and $479.7 \pm 54.5 \mu \mathrm{g} / \mathrm{paw}$, respectively. The $\mathrm{ED}_{30}$ values for systemic diclofenac and pyrilamine administration were $22.0 \pm 2.8 \mathrm{mg} / \mathrm{kg}$ and $48.8 \pm 6.0 \mathrm{mg} / \mathrm{kg}$, respectively.

The local peripheral administration of carrageenan produced a significant increase in the volume of the paws. The systemic administration of diclofenac and pyrilamine produced a dose-dependent anti-inflammatory effect $\left(p<0.05\right.$; Figure 3). The $\mathrm{ED}_{40}$ values for the individual anti-inflammatory activity of systemically administered diclofenac or pyrilamine were $48.7 \pm 5.9 \mathrm{mg} / \mathrm{kg}$ or $27.0 \pm 3.2 \mathrm{mg} / \mathrm{kg}$, respectively. At the end of the experiments, the animals were euthanized in a $\mathrm{CO} 2$ chamber. One hundred eighty rats were employed in these experiments.

Figures 1, 2 and 3 should be here.

\section{Interactions between diclofenac and pyrilamine}

Fixed-dose ratio combinations of diclofenac and pyrilamine were assayed and used to construct three dose-response curves. The final experimental $\mathrm{ED}_{30}$ or $\mathrm{ED}_{40}$ values were 183.3 $\pm 17.6 \mu \mathrm{g} / \mathrm{paw}, 18.1 \pm 1.9 \mathrm{mg} / \mathrm{kg}$, and $10.6 \pm 1.1 \mathrm{mg} / \mathrm{kg}$, for local antinociception, systemic antinociception, and anti-inflammation, respectively. These values were significantly lower ( $p$ $<0.05)$ than the theoretical $\mathrm{ED}_{30}$ or $\mathrm{ED}_{40}$ values $(343.4 \pm 28.9 \mu \mathrm{g} / \mathrm{paw}, 35.4 \pm 3.3 \mathrm{mg} / \mathrm{kg}$, and $37.9 \pm 3.4 \mathrm{mg} / \mathrm{kg}$, for the local antinociception, systemic antinociception and antiinflammation, respectively). The occurrence of synergistic interactions is shown in Figures 1, 2 and 3 by the experimental $\mathrm{ED}_{30}$ or $\mathrm{ED}_{40}$ values being below the additive effect threshold. Furthermore, the interaction index $(\gamma)$ values for the diclofenac-pyrilamine combinations $(0.53$ \pm 0.1 [local peripheral antinociception], $0.51 \pm 0.1$ [systemic antinociception] and $0.28 \pm 0.1$ [anti-inflammation]) were significantly different from unity. These results suggest that at both the local and systemic levels, the interaction between diclofenac and pyrilamine is synergistic 
in terms of antinociceptive and anti-inflammatory actions. At the end of the experiments, the animals were euthanized in a $\mathrm{CO}_{2}$ chamber. Ninety rats were employed in these experiments.

\section{Gastric injury}

For both intervals (Figures 4 and 5), the systemic administration of diclofenac, but not pyrilamine, caused hemorrhagic erosion of the stomach. The levels of gastric damage caused by the diclofenac and pyrilamine combinations $(17.7-35.4 \mathrm{mg} / \mathrm{kg}$ and $37.9 \mathrm{mg} / \mathrm{kg}$, at the third and sixth hour, respectively) were different from the damage measured in vehicle-treated animals $(p<0.05)$ (Figures 4 and 5). One hundred eighty rats were employed in these experiments.

Figures 4 and 5 should be here.

Effect of diclofenac, pyrilamine, and diclofenac + pyrilamine in combination on motor coordination

Systemic treatment with diclofenac, pyrilamine or the mixture of these drugs did not alter the motor capacity in the experimental animals (Table 2) $(p>0.05)$. At the end of the experiments, the animals were euthanized in a $\mathrm{CO}_{2}$ chamber. Twenty three rats were employed in these experiments.

\section{Table 2 should be here.}

\section{Discussion}

\section{Antinociceptive effect of diclofenac, pyrilamine and diclofenac-pyrilamine combinations}

In a normal tissue, pain is elicited by stimuli that potentially or actually damage the tissue. However, this physiological nociceptive pain is an alarm sensation that is absolutely critical for survival. Indeed, physiological nociceptive pain has the capacity to initiate an immediate and adequate escape response. The application of a harmful or damaging stimulus to a tissue causes pain and an inflammatory response, which are equal in magnitude to the 
intensity of the stimulus. In the formalin injury model, the chemical stimulus administered subcutaneously into a paw produces a typical nociceptive flinching behavior. Previous studies have shown that the late phase of the formalin test is blocked by NSAIDs such as diclofenac or ibuprofen (Ortiz 2011; Ortiz et al. 2012). Diclofenac is widely used for the treatment of several painful and inflammatory conditions (Gan 2010; Ortiz 2010; Ortiz et al. 2009). Unfortunately, NSAIDs possess a high incidence of adverse reactions, such as renal alterations and gastrointestinal damage (Gan 2010). In our study, diclofenac administered by both routes was able to decrease nociceptive behavior. This effect of diclofenac is due to a decrease in prostaglandin production. In addition, other mechanisms of action have been demonstrated for diclofenac, such as activation of the nitric oxide-cGMP- $\mathrm{K}^{+}$channels pathway, activation of metformin- and phenformin-dependent mechanisms, inhibition of $\mathrm{H}^{+}$gated channels, and production of kynurenate (an antagonist of the NMDA receptors) (Gan 2010; Ortiz 2011; 2013; Ortiz et al. 2012; Voilley et al. 2004). It is likely that the effects of diclofenac result from the interaction between several of these mechanisms of action. Furthermore, both the systemic and local peripheral administration of pyrilamine decreased the nociceptive behavior. Our results are consistent with the antinociceptive effects of pyrilamine observed in the formalin test realized by Mobarakeh et al. (2011). It was suggested that the pyrilamine-induced systemic and local peripheral antinociception could result from a blockade of the histamine receptors (Rosa and Fantozzi 2013). Nevertheless, other pyrilamine-induced effects cannot be excluded. Several pieces of evidence indicate that pyrilamine could produce an antinociceptive action via the activation of the $G_{i}$ protein pathway, the activation of the ATP-sensitive and $\mathrm{Ca}^{2+}$-gated $\mathrm{K}^{+}$channels, or the blockade of non-selective cation currents (Galeotti et al. 1999; 2002; Wang and Kotlikoff 2000).

In previous studies, the synergistic interaction between diclofenac and analgesics, neuromodulators, or plant extracts have been widely demonstrated using preclinical models 
(Acosta-Madrid et al. 2009; De Paz-Campos et al. 2014; Jiménez-Andrade et al. 2003; Picazo et al. 2006). In addition, we demonstrated a synergistic relaxing effect of a pyrilamine and paracetamol combination in the uterine tissue (Ortiz et al. 2011). Other authors demonstrated that combining sub-effective doses of pyrilamine and CGRP 8-37, a calcitonin gene-related peptide type $1\left(\mathrm{CGRP}_{1}\right)$ receptor antagonist, produced a synergistic antinociceptive effect on formalin-induced behavior (Mobarakeh et al. 2011). Our isobolographic analysis demonstrated a synergistic interaction between diclofenac and pyrilamine in both systemic and local peripheral antinociception. These effects can be due to the association or sum of the different mechanisms of action of both drugs. In other words, the diverse mechanisms induced by diclofenac (Gan 2010; Ortiz 2011; 2013; Ortiz et al. 2012; Voilley et al. 2004) are synergistically interacting with those of pyrilamine (Galeotti et al. 1999; 2002; Wang and Kotlikoff 2000) in the antinociceptive effect. Treatment with diclofenac, pyrilamine or the diclofenac + pyrilamine combinations did not alter motor coordination in the rats. Therefore, the antinociceptive effect induced by the drugs does not seem to result from a motor alteration.

\section{Anti-inflammation produced by single drugs and their combination}

The carrageenan-induced paw inflammation model is widely used to assess the antiinflammatory effects of drugs. The effect of carrageenan-induced edema is associated with a leukocyte response and the release of active substances, such as histamine, kinins, nitric oxide, serotonin, and prostaglandins (Marzocco et al. 2004; Nacife et al. 2004; Weissmann 1993). In the present study, an anti-inflammatory effect was observed with the systemic administration of diclofenac (Gan 2010). Likewise, pyrilamine administration elicited a significant anti-inflammatory effect at higher doses compared with those employed to block histamine-induced inflammation in the rat paws (Ezeamuzie and Umezurike 1989). Several authors found that pyrilamine produced only a weak, or even null, anti-inflammatory effect on 
the carrageenan-induced paw inflammatory response (Al-Haboubi and Zeitlin 1983; Ezeamuzie and Umezurike 1989; Singh et al. 2000). That is explained by the fact that those authors used doses ranging from 1 to $5 \mathrm{mg} / \mathrm{kg}$. In our study, we found a significant antiinflammatory effect at doses ranging between 10 and $56 \mathrm{mg} / \mathrm{kg}$. It is probable that the inhibition of the histamine receptors influences these effects. However, other mechanisms of action cannot be excluded. For example, the activation of the $\mathrm{G}_{\mathrm{i}}$ protein pathway and $\mathrm{K}^{+}$ channels or the blockade of non-selective cation currents could be involved (Galeotti et al. 1999; 2002; Ortiz et al. 2011; Wang and Kotlikoff 2000).

Our isobolographic analysis demonstrated a significantly synergistic interaction in the antiinflammatory effect induced by the diclofenac-pyrilamine mixture. Due to the participation of prostaglandins and histamine in the inflammatory reaction, it is very probable that the mixture is blocking the histamine receptors and prostaglandin production. However, the identification of the exact mechanism of action behind this synergism requires further investigation.

\section{Gastric damage produced by single drugs and their combination}

The introduction and acceptability of a new drug or combination of drugs are based on a satisfactory balance between the benefits and risks. Many experimental and clinical investigations demonstrated the benefits and gastrointestinal damage of NSAIDs. Several therapeutic strategies have been employed to increase the efficacy and decrease the gastrointestinal damage risk of NSAIDs (Lazzaroni and Porro 2009). Therefore, we evaluated the gastric damage produced by diclofenac and pyrilamine alone or in combination. Diclofenac produced significant gastric injury at 3 and 6 hours. Additionally, insignificant gastric lesions were produced by pyrilamine alone in all animals at 3 and 6 hours. The highest dose of the diclofenac-pyrilamine combination produced serious gastric injury (17.7- 35.4 $\mathrm{mg} / \mathrm{kg}$ and $37.9 \mathrm{mg} / \mathrm{kg}$, at the third and sixth hour, respectively). However, the gastric damage scores resulting from the highest doses of diclofenac + pyrilamine systemic administration at 
three and six hours appeared lower than the scores resulting from the highest doses of diclofenac alone. The use of a lower diclofenac dose in the combination suggests that the present mixture could be a beneficial therapeutic option. However, the advantage of this combination at the gastric toxicity level in the clinic requires further investigation.

Experimental animal models are an important resource for studying human diseases. Animals such as rodents and larger species have been largely employed to determine the physiopathology of various painful conditions and serve as experimental basis for mechanistic investigations and testing new therapeutic interventions. Although there are not animal models that mimic acute or chronic clinical pain conditions with complete fidelity, several animal models are used to evaluate the security and efficacy of NSAIDs and non-NSAIDs. In the present study, the efficacy and security of the diclofenac-pyrilamine combination were assessed on the rat formalin test. The diclofenac and pyrilamine oral dose used in the present study appear to be larger than those dose employed clinically (Derry et al. 2015; Ortiz 2010; Standing et al. 2011). It is probable that the observed difference may be due to species differences in absorption, metabolism, plasma protein binding, central nervous system and tissue penetration, the kind and severity of pain or other factors altering availability of diclofenac and pyrilamine at the target tissues (Jimenez-Andrade et al. 2003; Whiteside and Kennedy 2010). Studies have found that the drug dose to demonstrate efficacy are higher in rats than in humans (Jimenez-Andrade et al. 2003; Moran and Courtney 2016; Whiteside and Kennedy 2010). The real contribution of the diclofenac-pyrilamine combination in clinical situation await validation and therefore caution is warranted in using these results to predict clinical efficacy in pain conditions.

The different combinations improved the anti-inflammatory and analgesic profiles compared with diclofenac or pyrilamine alone. Similarly, the level of gastric damage was reduced with the combination of drugs compared with the NSAID diclofenac alone. This 
combination could be tested for the relief of mild to moderate inflammatory pain and for the relief of common cold symptoms in patients.

\section{Conflict of Interest statement}

The author declares that there are no conflicts of interest.

\section{References}

Acosta-Madrid, I.I., Castañeda-Hernández, G., Cilia-López, V.G., Cariño-Cortés, R., PérezHernández, N., Fernández-Martínez, E., and Ortiz, M.I. 2009. Interaction between Heliopsis longipes extract and diclofenac on the thermal hyperalgesia test. Phytomedicine, 16: 336-341.

Al-Haboubi, H.A., and Zeitlin, I.J. 1983. Re-appraisal of the role of histamine in carrageenaninduced paw oedema. Eur. J. Pharmacol. 88:169-176.

Bignotto, L., Rocha, J., Sepodes, B., Eduardo-Figueira, M., Pinto, R., Chaud, M., de Carvalho, J, Moreno, H. Jr., and Mota-Filipe, H. 2009. Anti-inflammatory effect of lycopene on carrageenan-induced paw oedema and hepatic ischaemia-reperfusion in the rat. Br. J. Nutr. 10: $1-8$.

De Paz-Campos, M.A., Ortiz, M.I., Chávez Piña, A.E., Zazueta-Beltrán, L., and CastañedaHernández, G. 2014. Synergistic effect of the interaction between curcumin and diclofenac on the formalin test in rats. Phytomedicine, 21: 1543-1548.

Derry, S., Wiffen, P.J., and Moore, R.A. 2015. Single dose oral diclofenac for acute postoperative pain in adults. Cochrane Database Syst. Rev. 7: CD004768.

Ezeamuzie, C.I., and Umezurike, C.C. 1989. Effect of histamine H2-receptor antagonists on acute inflammatory of the rat paw oedema. J. Pharm. Pharmacol. 41: 261-265. 
Fujita, T., Ohue, M., Fujii, Y., Jotoku, T., Miyauchi, A., Takagi, Y., Tsuchiya, M., and Endo, Y. 2013 Prompt analgesic effect of antihistaminic diphenhydramine ointment on bonejoint-muscle pain as assessed by skin impedance. Pharmacology, 92: 158-166.

Galeotti, N., Ghelardini, C., and Bartolini, A. 1999. The role of potassium channels in antihistamine analgesia. Neuropharmacology, 38: 1893-1901.

Galeotti, N., Ghelardini, C., and Bartolini, A. 2002. Antihistamine antinociception is mediated by Gi-protein activation. Neuroscience, 109: 811-818.

Gan, T.J. 2010. Diclofenac: an update on its mechanism of action and safety profile. Curr. Med. Res. Opin. 26: 1715-1731.

Jiménez-Andrade, J.M., Ortiz, M.I., Pérez-Urízar, J., Aguirre-Bañuelos, P., Granados-Soto, V., Castañeda-Hernández, G. 2003. Synergistic effects between codeine and diclofenac after local, spinal and systemic administration. Pharmacol. Biochem. Behav. 76: 463-471.

Kim, S.Y., Chang, Y.J., Cho, H.M., Hwang, Y.W., and Moon, Y.S. 2015. Non-steroidal antiinflammatory drugs for the common cold. Cochrane Database Syst. Rev. 9: CD006362.

Lazzaroni, M., and Porro, G.B. 2009. Management of NSAID-induced gastrointestinal toxicity: focus on proton pump inhibitors. Drugs, 69: 51-69.

Marzocco, S., Di Paola, R., Serraino, I., Sorrentino, R., Meli, R., Mattaceraso, G., Cuzzocrea, S., Pinto, A., and Autore, G. 2004. Effect of methylguanidine in carrageenan-induced acute inflammation in the rats. Eur. J. Pharmacol. 484: 341-350.

Mobarakeh, J.I., Torkaman-Boutorabi, A., Rahimi, A.A., Ghasri, S., Nezhad, R.M., Hamzely, A., Khoshkholgh Sima, B., Takahashi, K., Nunoki, K., and Yanai, K. 2011. Interaction of histamine and calcitonin gene-related peptide in the formalin induced pain perception in rats. Biomed. Res. 32: 195-201. 
Moore, R.A., Derry, S., Aldington, D., and Wiffen, P.J. 2015. Single dose oral analgesics for acute postoperative pain in adults - an overview of Cochrane reviews. Cochrane Database Syst. Rev. 9: CD008659.

Moran, C.P., and Courtney, A.E. 2016. Managing acute and chronic renal stone disease. Practitioner, 260: 17-20.

Nacife, V.P., Soeiro Mde, N., Gomes, R.N., D’Avila, H., Castro-Faria Neto, H.C., and Meirelles Mde, N. 2004. Morphological and biochemical characterization of macrophages activated by carrageenan and lipopolysaccharide in vivo. Cell Struct. Funct. 29: 27-34.

Nalamachu, S. 2013. An overview of pain management: the clinical efficacy and value of treatment. Am. J. Manag. Care, 19: s261-s266.

Ortiz, M.I., Rangel-Flores, E., Carrillo-Alarcón, L.C., and Veras-Godoy, H.A. 2009. Prevalence and impact of primary dysmenorrhea among Mexican high school students. Int. J. Gynecol. Obst. 107: 240-243.

Ortiz, M.I. 2010. Primary dysmenorrhea among Mexican university students: prevalence, impact and treatment. Eur. J. Obst. Gynecol. Rep. Biol. 152: 73-77.

Ortiz, M.I., González-García, M.P., Ponce-Monter, H.A., Castañeda-Hernández, G., and Aguilar-Robles, P. 2010a. Synergistic effect of the interaction between naproxen and citral on inflammation in rats. Phytomedicine, 18: 74-79.

Ortiz, M.I., Ramírez-Montiel, M.L., González-García, M.P., Ponce-Monter, H.A., and Castañeda-Hernández, G. 2010b. Examination of the effects of the interaction between naproxen and citral on nociception and gastric damage in rats. Arch. Pharm. Res. 33: 1691-1697.

Ortiz, M.I. 2011. Blockade of the antinociception induced by diclofenac, but not of indomethacin, by sulfonylureas and biguanides. Pharmacol. Biochem. Behav. 99: 1-6. 
Ortiz, M.I., Ponce-Monter, H.A., Mora-Rodríguez, J.A., Barragán-Ramírez, G., and BarrónGuerrero, S. 2011. Synergistic relaxing effect of the paracetamol and pyrilamine combination in isolated human myometrium. Eur. J. Obst. Gynecol. Rep. Biol. 157: $22-26$.

Ortiz, M.I., Castañeda-Hernández, G., Izquierdo-Vega, J.A., Sánchez-Gutiérrez, M., PonceMonter, H.A., and Granados-Soto, V. 2012. Role of ATP-sensitive $\mathrm{K}^{+}$channels in the antinociception induced by non-steroidal anti-inflammatory drugs in streptozotocindiabetic and non-diabetic rats. Pharmacol. Biochem. Behav. 102: 163-169.

Ortiz, M.I. 2013. Synergistic Interaction between metformin and sulfonylureas on the antinociception induced by diclofenac on the formalin test in rats. Pain Res. Manag. 18: $253-258$.

Picazo, A., Castañeda-Hernández, G., and Ortiz, M.I. 2006. Examination of the interaction between peripheral diclofenac and gabapentin on the $5 \%$ formalin test in rats. Life Sci. 79: 2283-2287.

Raffa, R.B. 2001. Antihistamines as analgesics. J. Clin. Pharm. Ther. 26: 81-85.

Rosa, A.C., and Fantozzi, R. 2013. The role of histamine in neurogenic inflammation. Br. J. Pharmacol. 170: 38-45.

Rumore, M.M., and Schlichting, D.A. 1986. Clinical efficacy of antihistaminics as analgesics. Pain, 25: 7-22.

Singh, H., Kumar, S., Dewan, S., and Kumar, V.L. 2000. Inflammation induced by latex of Calotropis procera--a new model to evaluate anti-inflammatory drugs. J. Pharmacol. Toxicol. Methods, 43: 219-224.

Standing, J.F., Tibboel, D., Korpela, R., and Olkkola, K.T. 2011. Diclofenac pharmacokinetic meta-analysis and dose recommendations for surgical pain in children aged 1-12 years. Paediatr. Anaesth. 21: 316-324. 
Tallarida, R.J. 2000. Drug Synergism and Dose-Effect Data Analysis. Chapman \& Hall/CRC New York. pp. 1-72.

Tallarida, R.J. 2002. The interaction index: a measure of drug synergism. Pain, 98: 163-168.

Voilley, N. 2004. Acid-sensing ion channels (ASICs): new targets for the analgesic effects of non-steroid anti-inflammatory drugs (NSAIDs). Curr. Drug Targets Inflamm. Allergy, 3: $71-79$.

Wagner, H., and Ulrich-Merzenich, G. 2009. Synergy research: Approaching a new generation of phyto-pharmaceuticals. Phytomedicine, 16: 97-110.

Wang, Y.X., and Kotlikoff, M.I. 2000. Signalling pathway for histamine activation of nonselective cation channels in equine tracheal myocytes. J. Physiol. 523: 131-138.

Weissmann, G. 1993. Prostaglandins as modulators rather than mediators of inflammation. J. Lipid Mediat. 6: 275-286.

Whiteside, G.T., and Kennedy, J.D. 2010. Consideration of pharmacokinetic pharmacodynamic relationships in the discovery of new pain drugs. In Translational Pain Research: From Mouse to Man. Edited by L. Kruger and A.R. Light. Boca Raton, FL, CRC Press/Taylor \& Francis. Chapter 16.

Winter, C.A., Risley, E.A., and Nuss, G.W. 1962. Carrageenan-induced edema in hind paw of the rat as an assay for antiinflammatory drugs. Proc. Soc. Exp. Biol. Med. 111: 544547.

Zimmermann, M. 1983. Ethical guidelines for investigations of experimental pain in conscious animals. Pain, 16: 109-110. 
Table 1. Diclofenac-pyrilamine combinations doses.

\begin{tabular}{|c|c|c|c|c|c|}
\hline \multicolumn{2}{|c|}{$\begin{array}{l}\text { Local peripheral } \\
\text { Antinociception }\end{array}$} & \multicolumn{2}{|c|}{ Systemic antinociception } & \multicolumn{2}{|c|}{ Anti-inflammation } \\
\hline Diclofenac & Pyrilamine & Diclofenac & Pyrilamine & Diclofenac & Pyrilamine \\
\hline$\mu \mathrm{g} / \mathrm{paw}$ & $\mu \mathrm{g} / \mathrm{paw}$ & $\mathrm{mg} / \mathrm{kg}$ & $\mathrm{mg} / \mathrm{kg}$ & $\mathrm{mg} / \mathrm{kg}$ & $\mathrm{mg} / \mathrm{kg}$ \\
\hline $\mathrm{ED}_{40} / 2$ : & $\mathrm{ED}_{40} / 2$ : & $\mathrm{ED}_{30} / 2:$ & $\mathrm{ED}_{30} / 2:$ & $\mathrm{ED}_{40} / 2$ : & $\mathrm{ED}_{40} / 2$ : \\
\hline 103.55 & 239.85 & 11.00 & 24.4 & 13.50 & 24.35 \\
\hline $\mathrm{ED}_{40} / 4:$ & $\mathrm{ED}_{40} / 4:$ & $\mathrm{ED}_{30} / 4:$ & $\mathrm{ED}_{30} / 4:$ & $\mathrm{ED}_{40} / 4:$ & $\mathrm{ED}_{40} / 4:$ \\
\hline 51.78 & 119.93 & 5.5 & 12.2 & 6.75 & 12.18 \\
\hline $\mathrm{ED}_{40} / 8:$ & $\mathrm{ED}_{40} / 8:$ & $\mathrm{ED}_{30} / 8:$ & $\mathrm{ED}_{30} / 8:$ & $\mathrm{ED}_{40} / 8:$ & $\mathrm{ED}_{40} / 8:$ \\
\hline 25.89 & 59.96 & 2.75 & 6.1 & 3.38 & 6.09 \\
\hline $\mathrm{ED}_{40} / 16:$ & $\mathrm{ED}_{40} / 16$ : & $\mathrm{ED}_{30} / 16:$ & $\mathrm{ED}_{30} / 16:$ & $\mathrm{ED}_{40} / 16:$ & $\mathrm{ED}_{40} / 16:$ \\
\hline 12.94 & 29.98 & 1.38 & 3.05 & 1.69 & 3.04 \\
\hline
\end{tabular}

$\mathrm{ED}=$ Effective dose 
Table 2. Effect of diclofenac, pyrilamine or the combination of these drugs on the motor coordination in the rats

\begin{tabular}{lccc}
\hline & \multicolumn{3}{c}{ Time after the drug administration } \\
\cline { 2 - 4 } & $11 \mathrm{~h}$ & $3 \mathrm{~h}$ & $6 \mathrm{~h}$ \\
\hline Control & $118.8 \pm 0.9$ & $118.8 \pm 0.9$ & $119.4 \pm 1.3$ \\
Diclofenac $(56 \mathrm{mg} / \mathrm{kg})$ & $118.3 \pm 1.7$ & $119.2 \pm 0.9$ & $118.3 \pm 1.7$ \\
Pyrilamine $(56 \mathrm{mg} / \mathrm{kg})$ & & & \\
Diclofenac $(13.5 \mathrm{mg} / \mathrm{kg})+$ & $116.7 \pm 1.7$ & $119.2 \pm 0.9$ & $118.3 \pm 1.7$ \\
Pyrilamine $(24.4 \mathrm{mg} / \mathrm{kg})$ & & & \\
\hline
\end{tabular}

Rats were pretreated with vehicle $(\mathrm{VEH})$ or the different drugs before the rotarod test. All the animals walked during a 120 seconds period at the basal time (0-min). Data are expressed as seconds. Each point corresponds to the mean \pm SEM of 5-8 animals. 


\section{Figure captions}

Figure 1. (A and B) Diclofenac- and pyrilamine-induced local antinociceptive effect in the formalin model. Before the injection of formalin, the animals were pretreated locally with vehicle (VEH), diclofenac, or pyrilamine. (C) Diclofenac-pyrilamine combination-induced local antinociceptive effect. Results are shown as the $\%$ of the effects. Data are presented as the mean \pm SEM for 5-8 animals. *, significantly different $(p<0.05)$, using the ANOVA and the Dunnett's test. (D) Isobologram showing the kind of interaction produced by the diclofenac-pyrilamine combination. T, theoretical additive value; E, experimental ED value.

Figure 2. (A and B) Diclofenac- and pyrilamine-induced systemic antinociceptive effect in the formalin model. Before the injection of formalin, the animals were pretreated systemically with vehicle (VEH), diclofenac, or pyrilamine. (C) Diclofenac-pyrilamine combinationinduced systemic antinociceptive effect. Results are shown as the \% of the effects. Data are presented as the mean \pm SEM for 5-8 animals. *, significantly different $(p<0.05)$, using the ANOVA and the Dunnett's test. (D) Isobologram showing the kind of interaction produced by the diclofenac-pyrilamine combination. $\mathrm{T}$, theoretical additive value; $\mathrm{E}$, experimental $\mathrm{ED}$ value.

Figure 3. (A and B) Diclofenac- and pyrilamine-induced systemic anti-inflammatory effect in the carrageenan test. Before the injection of carrageenan, the animals were pretreated systemically with vehicle (VEH), diclofenac, or pyrilamine. (C) Diclofenac-pyrilamine combination-induced systemic anti-inflammatory effect. Results are shown as the \% of the effects. Data are presented as the mean \pm SEM for 5-8 animals. ${ }^{*}$, significantly different $(p<$ 0.05), using the ANOVA and the Dunnett's test. (D) Isobologram showing the kind of interaction produced by the diclofenac-pyrilamine combination. $\mathrm{T}$, theoretical additive value; E, experimental ED value. 
Figure 4. Gastric injury produced by diclofenac, pyrilamine and the diclofenac-pyrilamine combination. The rats were pretreated with vehicle (VEH), diclofenac, pyrilamine, or a diclofenac-pyrilamine combination three hours prior to euthanasia. The stomachs were removed, and hemorrhagic damage was scored. Each value corresponds to the average $\pm \mathrm{SEM}$ for 5-8 animals. *, significantly different $(p<0.05)$ using the ANOVA and the Dunnett's test. Figure 5. Gastric injury produced by diclofenac, pyrilamine and the diclofenac-pyrilamine combination. The rats were pretreated with vehicle (VEH), diclofenac, pyrilamine, or a diclofenac-pyrilamine combination six hours prior to euthanasia. The stomachs were removed, and hemorrhagic damage was scored. Each value corresponds to the average \pm SEM for 5-8 animals. *, significantly different $(p<0.05)$ using the ANOVA and the Dunnett's test. 

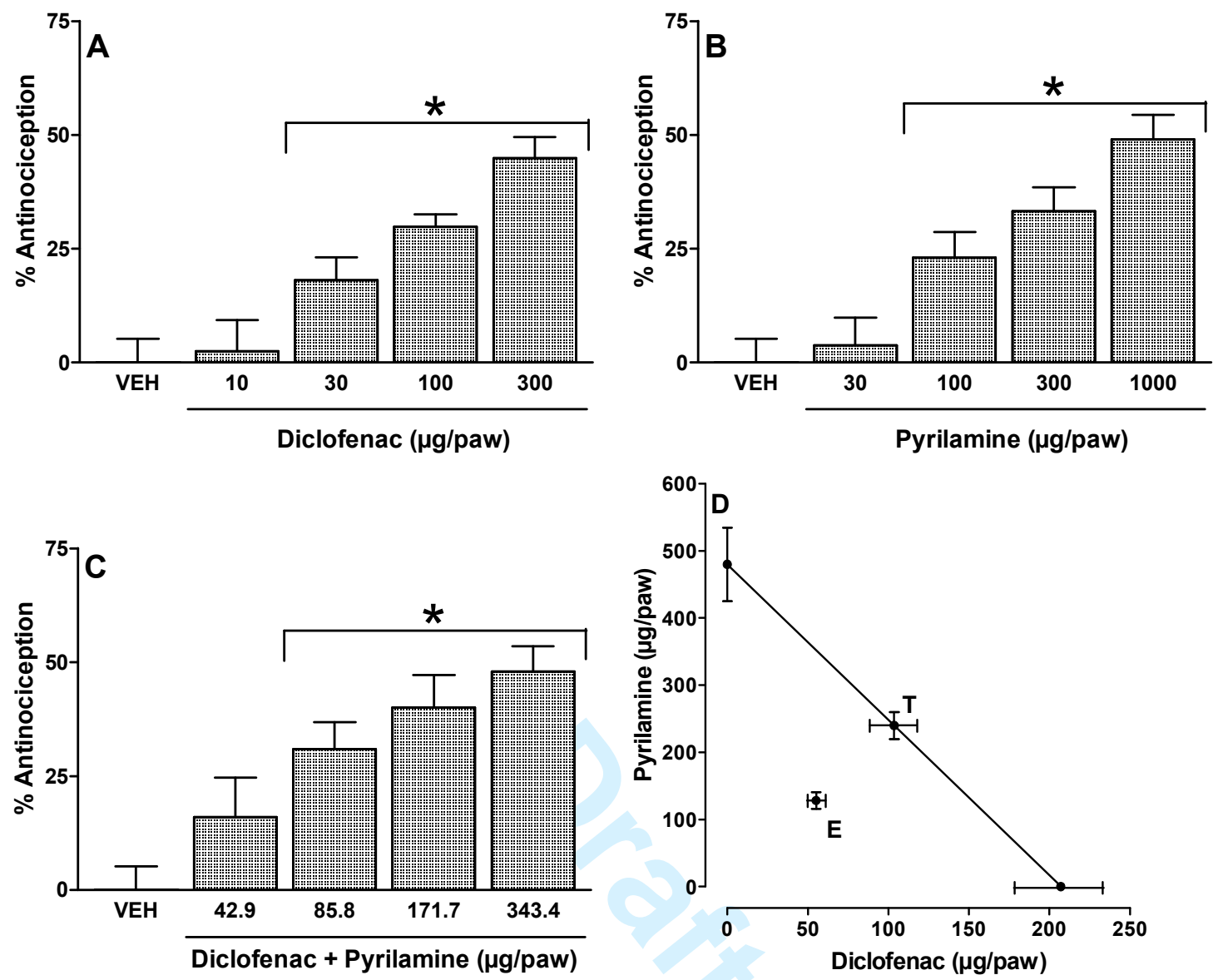

Figure 1. 

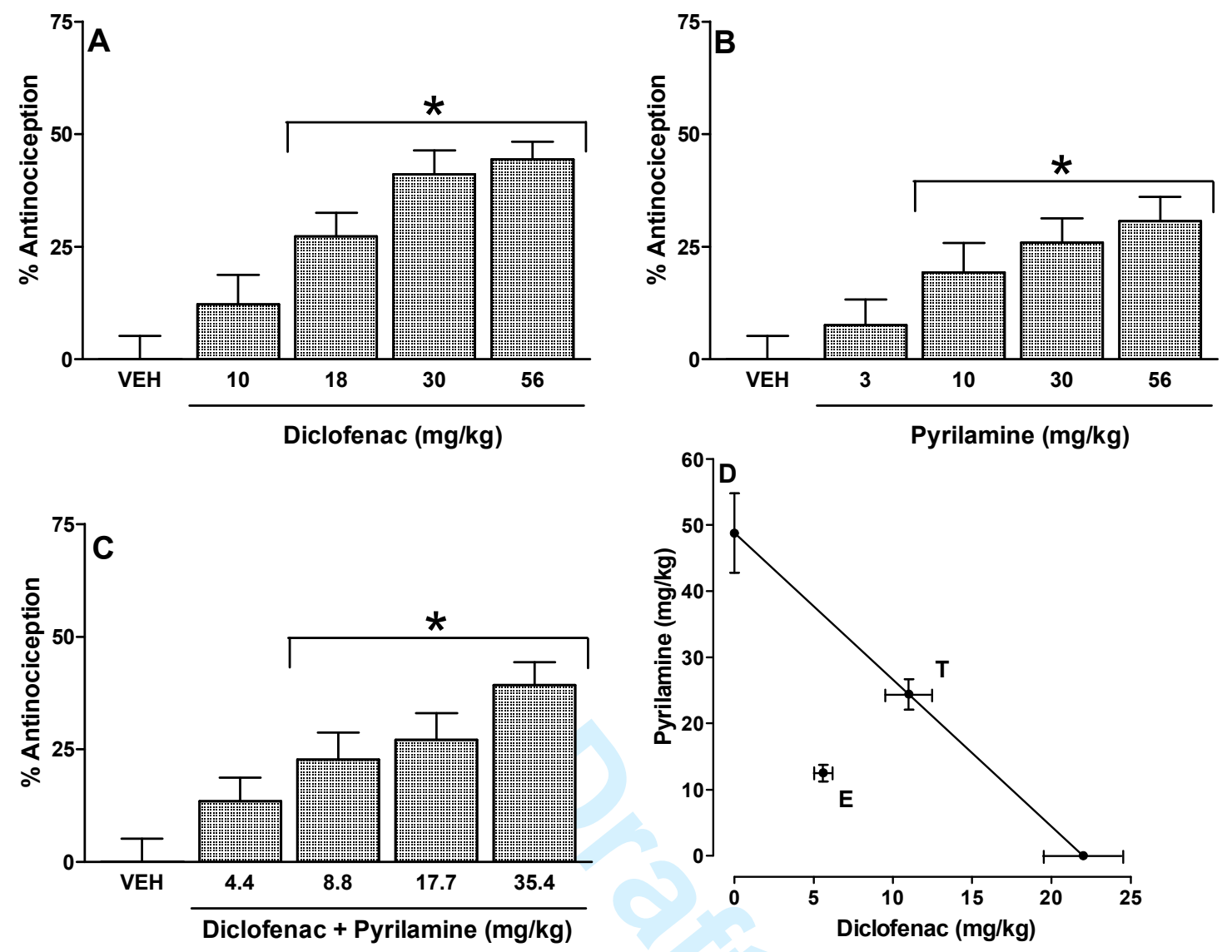

Figure 2. 

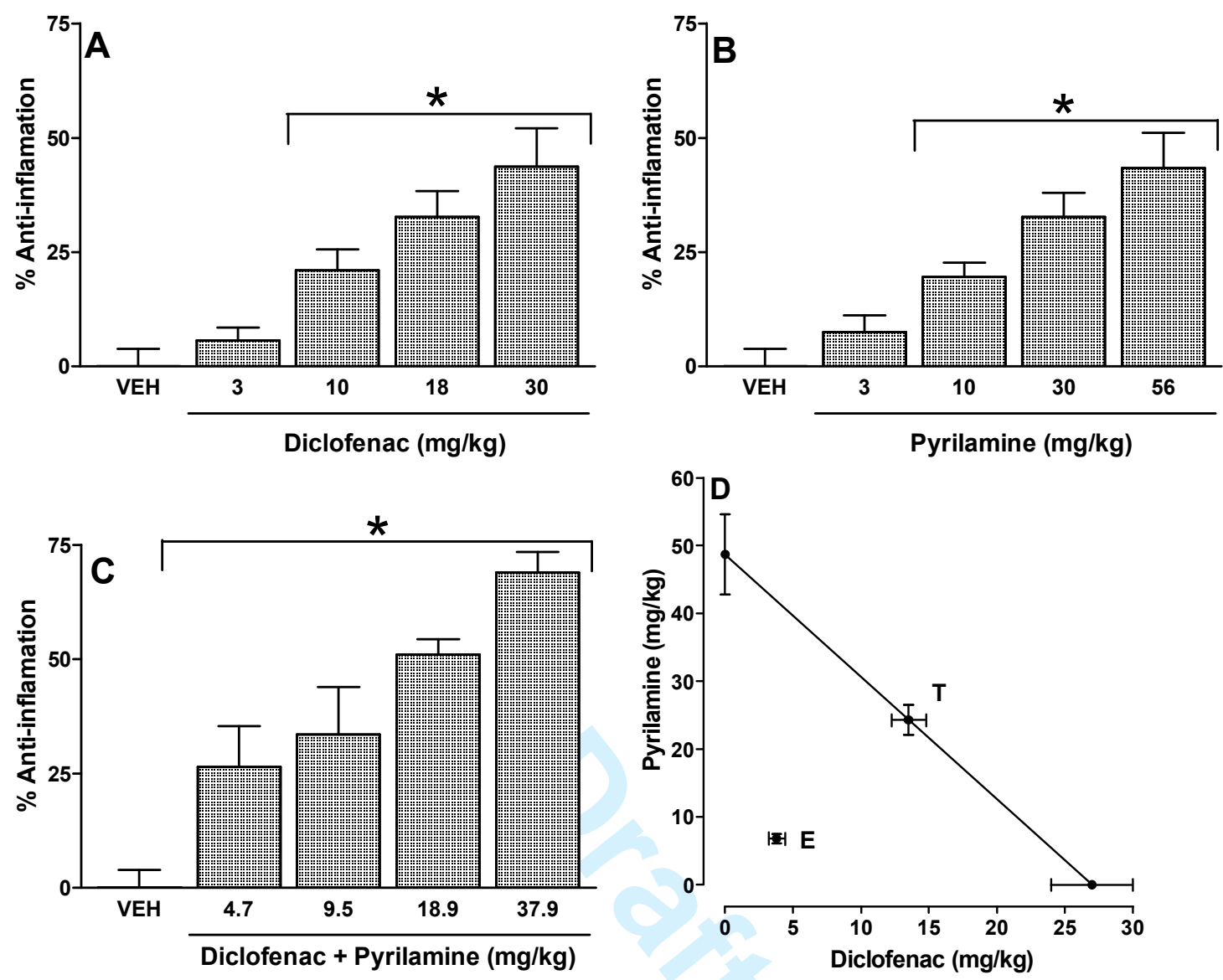

Figure 3. 


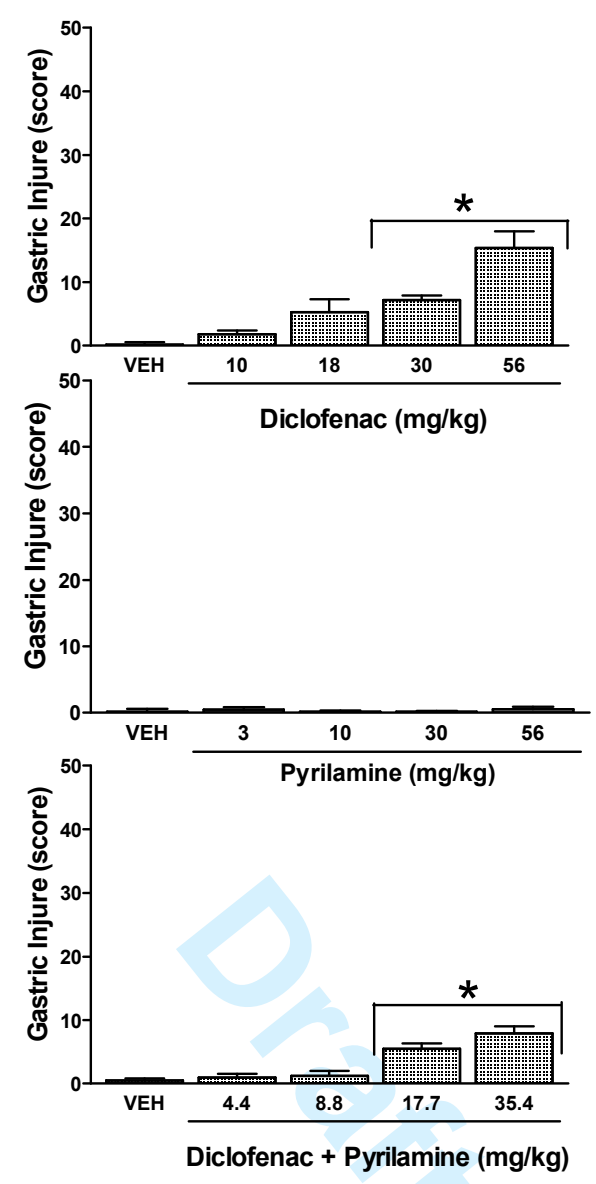

Figure 4. 

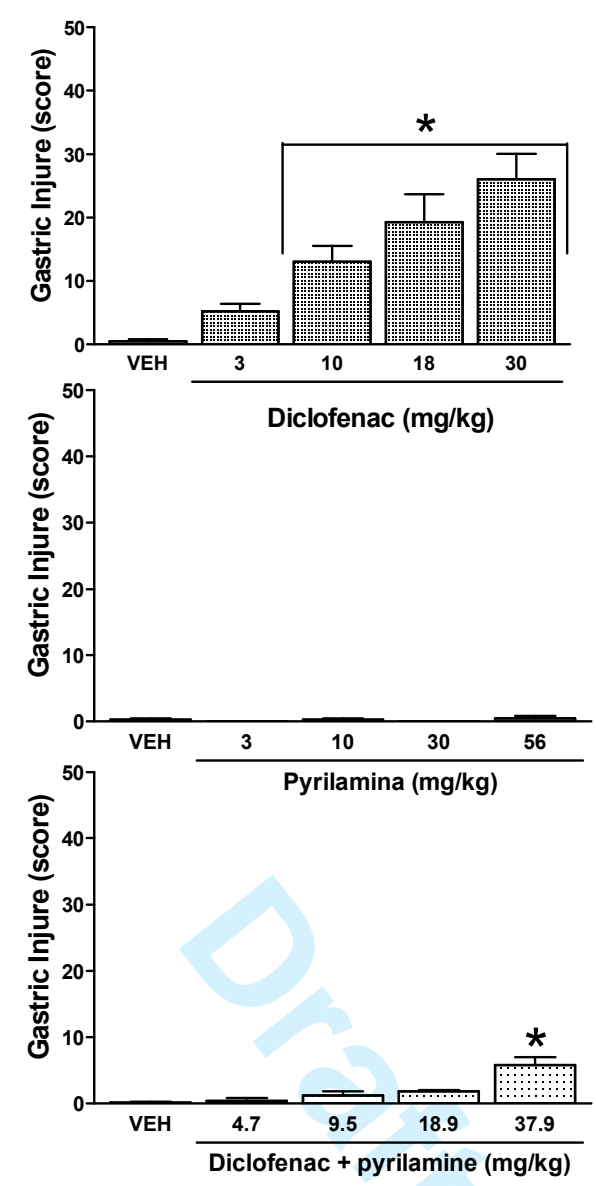

Figure 5. 